\title{
THE PUBLIC RELATIONS OF SCIENCE*
}

\author{
By Dr. Wesley C. Mitchell, \\ Professor of ECONOMICS, Columbia University
}

$\mathrm{U}$ NTIL recently the attitude of the public toward science seemed to be growing more appreciative. There have always been folk who objected strenuously to the supposed implications of certain scientific hypotheses, but on the whole science was generally esteemed the most progressive factor in culture, man's best hope for bettering his lot upon earth. Of late this tide of approval has ebbed. There is a widespread disposition to hold science responsible for the ills men are bringing upon themselves-for technological employment, for the rise of autocracies, for the suppression of freedom, for the heightened horrors of war. For their part, scientific men are appalled at the hideous uses to which their discoveries are put. They feel an urge to combat the misuses of science, to protect the social values they cherish, but what they can do is not clear. The quandary is one that all who cherish science should face, however unwelcome and difficult the task.

I

Let me start by recalling certain changes in the relations of science to society that may help us see our present problems in historical perspective.

The beginnings of scientific knowledge have been traced to man's dealings with the implements of his daily life-the sticks and stones, the skins, fibres, and clay he shaped to his uses, and in the shaping learned to know. At a later stage of cultural advance, thinking about natural phenomena, like thinking about religious observances, tended to break away from direct associations with daily work. Such efforts to understand the world as the Middle Ages made were concerned chiefly with problems of a divine dispensation. Observation was not pertinent, and factual tests of conclusions were not possible.

The re-birth of science in the sixteenth and seventeenth centuries was accomplished by turning from the study of concepts back to the study of Nature. The new orientation was characterized by close observation, by the invention of devices to make observation more penetrating and accurate, by purposeful experimentation to simplify the processes observed, by close attention to quantity as well as to quality, by the practical application of mathematics to express the relations

* From the address of the retiring president of the American Association for the Advancement of Science, delivered on December 27 at Columbus, Ohio. observed, by reformulation of concepts to fit the findings, by critical checking of one investigator's work by others, by the cumulation of tested conclusions in old fields of research, and by the extension of this mode of inquiry to new fields. Inventing instruments for observing, setting up experiments, measuring, and testing brought science again into intimate touch with the practical arts. Investigators took a keen interest in current affairs, sought to profit by the skill of craftsmen, and to put what they learned to practical uses. Discoveries were applied not only to the production of goods, but also to navigation, fortification, ballistics, and administration. By the close of the seventeenth century the dramatic achievements of 'natural philosophy' were leading many to expect an almost limitless advance, and the promotion of science was recognized as a proper object of public policy. Kings lent their patronage to scientific societies. Philanthropists followed the royal precedents by offering prizes for improvements in the arts and later by endowing research.

Of course the public relations of science were not uniformly harmonious in this age of genius. But the celebrated clashes between scientific discoveries and beliefs held by churchmen did not affect many lines of inquiry and did not gravely retard the rising tide of investigation. Not less characteristic of the age than Galileo's troubles were Newton's services to churchly teachings and to the State. Scientific men have lamented that he devoted his later years to arguing the validity of biblical prophecies; they have paid less attention to his work as Warden of the Mint. It was adjustments in the weights of the guinea and the shilling suggested by Newton that gave England a de facto gold standard in the eighteenth century.

An even more striking example of close relations between research and service to mankind is the life of Benjamin Franklin. The foremost American discoverer of his time, he was foremost also in applying and disseminating science to make life more comfortable, more secure, more interesting, more humane. These activities were incidents in the life of a busy printer, editor, politician, postmaster, legislator, colonial agent, and diplomat. But while we wonder at the extraordinary versatility of a man who could become both a scientific discoverer and a great statesman under any conditions, we must remember that in Franklin's day science was still in its 'natural philosophy' stage. 
With the cumulation of results, science became a more exacting mistress, requiring of her votaries more exclusive attention. But science did not draw away from the material tasks of daily life as it had in Greece. On the contrary, these relations were becoming more intimate, while scientists were learning to speak symbolic dialects less and less intelligible to the public or even to one another. Let me illustrate the seeming paradox by the relations between science and industry.

To most of us the modern age is characterized by technological progress as markedly as by scientific discovery. We think of the two achievements as interdependent. This interdependence was less obvious to Franklin's contemporaries than to us. Theirs was a century of great inventions, but inventions made mostly by men not trained in science. The captains of industry who carried the Industrial Revolution through its youthful phases were often technical experts, business executives, and capitalists united in one person. Men of this versatile type are still to be found even in 'big business'; but they are becoming as rare as once they were common. For, as technology was elaborated, experts with special training were required to supervise its operations.

The economic results produced by this unplanned organization of mutually stimulating activities astonished mankind. Industry after industry reorganized its processes time and again to take advantage of the latest engineering applications of scientific discoveries, and new industries kept cropping up. The efficiency of human labour increased greatly, per capita income rose, and hours of labour declined. Higher standards of living, and applications of science to the prevention and cure of disease, reduced death-rates and prolonged the average duration of life. Population grew rapidly in the nations that led the scientific procession, and spread where it would over the earth, dominating, exploiting, sometimes exterminating the non-scientific peoples. Life became ampler if not easier for the beneficiaries of science.

What industry owed science it repaid in many ways. It provided in bewildering variety laboratory equipment more accurate and powerful than that made by hand. It stood ready to construct any new contrivance an investigator designed, and often improved upon the original plans. Fortunes accumulated in business were the source of many scientific endowments. Business corporations granted research funds to universities, and set up research staffs of their own, which were sometimes permitted to work upon fundamental problems.

Governments recognized the social importance of science by making place for an expanding array of scientific courses in public schools and universities, and by undertaking wide-ranging programmes of research. In the United States, the Federal Government became the largest employer of scientific men. At the time of the Civil War it chartered the Academy of Sciences, and in the War of 1914-18, the National Research Council to advise it upon scientific problems; in 1934, it set up the organization that has developed into the National Resources Planning Board, with affiliations covering the full gamut of the sciences.

Finally, the public at large had a share in these great changes. It was the ultimate beneficiary of reductions in costs of production, of increasing per capita output, of new types of consumers' goods, of shorter working hours, of better protection against disease, of free education.

In short, this policy of laisser-faire worked wonders. Science helped industry and industry helped science. Even the backward art of agriculture, which faces so many difficulties and uncertainties, was benefiting by research. The dreaded 'law of diminishing returns' seemed to be overbalanced by improvements in practice based upon the work of soil chemists, botanists and geneticists. The frightful prospect of overpopulation that Malthus had taught the thoughtful to fear seemed to be dissipated by scientific agriculture and scientific techniques of contraception. Best of all, science seemed to have found the secret of illimitable progress.

\section{II}

I doubt that any scientist ever accepted without qualification this idyllic version of the benefits science confers upon mankind. Certainly there were numerous protests from scientific quarters against misuses of the new technology. Geologists and economists warned against the rapid depletion of mineral deposits. Chemists feared for the nitrogen content of the soil. Geographers and meteorologists protested that wholesale cutting of forests and the ploughing of grass lands produced deserts. Biologists lamented the extinction of animal species and anthropologists the callous stamping out of simpler cultures. Social scientists found much amiss within the countries that were most progressive. Urban and rural slums persisted as centres of disease and crime. The need of securing capital to utilize the new technology put control over it into the hands of the propertied classes. Labour was often grievously exploited. Huge fixed investments that could be used for only one purpose made competition destructive. The obvious escape from these hazards was to form monopolistic combinations. That was pleasant for the monopolists, but not for other business men or for consumers. Besides the obvious dangers of 
exploitation, many feared that the great combinations might purposely slow down technological advance because it threatened rapid obsolescence of their equipment.

Business did not manage even its own interests properly, for every few years it generated a crisis and depression in which it suffered along with the whole community ; and the international relations of the scientifically advanced peoples showed at his worst "the old savage in the new civilization". Demonstrations of the economic advantages of free trade no more stopped the imposition of protective tariffs than demonstrations of the horrors of war kept peace. Militant nationalism seemed to be spreading and growing more passionate. An appreciable fraction of scientific energy was devoted to contriving weapons of destruction. Thus against the glowing pictures of science as a benefactor of mankind could be set a dark picture of science putting more power into the hands of certain individuals, classes, nations, generations, giving them a differential advantage over others which they exploited according to their several natures.

Though some of the Jeremiads I have been recalling belong to an earlier time, they did not produce a profound effect upon the public relations of science until recently. The ills complained of could be regarded as 'growing pains'. They represented social 'problems', which should be dealt with by arousing public opinion in a campaign of education that would lead to remedial legislation. Problems that could not be solved by this time-honoured method would yield presumably to the slower processes of general enlightenment.

This optimistic attitude was particularly characteristic of democratic nations. It assumed tacitly that experts could devise whatever 'reforms' were needed, and that the majority of voters were intelligent enough to understand, and well disposed enough to support, desirable changes. Science had a stellar role in this programme for remedying the ills incidental to progress. It did not claim knowledge of good and evil ; but it enabled men to make their value-judgments more intelligent by tracing the consequences of actions. Many people were devoting their energies to the study of social problems ; they spoke optimistically of their subjects as social 'sciences'. It seemed not too much to hope that science might presently begin to guide social practice in somewhat the same fashion as it guided practice in industry and medicine.

\section{III}

That the public relations of science have recently become disturbing both to the public and to scientists is due, not to any change in the character of science or the behaviour of scientists, but to changes in social conditions. While most people approved on the whole of the applications of science before 1914, they have come to dislike many of the effects produced by later applications. To be specific: when scientific improvements in one industry after another threw men out of work in earlier decades, the victims might suffer in silence or protest riotously and perhaps smash machines. But the public at large was not deeply concerned over their sufferings; it repressed disorder, expected the displaced men to find new jobs for themselves, and blessed science for reducing costs of production. Now that a larger part of the public suffers from loss of work or obsolescence of investments, science is blamed for technological unemployment. When the modern arts of communication were used to facilitate the political processes of democratic nations, they were extolled on all sides. Now that these arts, further improved, are controlled in some countries by autocratic Governments and used to suppress opposition, many good people treat science as the culprit. When the scientific nations used their superior arms against backward peoples, only a few sensitive souls were wrathful over the unfairness or iniquity of the procedure. Most people felt that science was good when it gave them a decisive advantage over those they wished to 'civilize'. Now that these same nations are threatened by still more terrible weapons in the hands of their peers, their moral horror is sincere, and they wish scientific warfare back to the pit from which it was digged.

This shift in attitude toward science as one happens to benefit or suffer from its applications is doubtless a mark of human frailty, but it is one at which scientists should not cavil without recalling a similar frailty of their own. Now that we are on the defensive, we discover that science is neither good nor bad in itself, but is merely an instrument that can be put to good or bad uses, and that the blame for bad uses should be visited upon those responsible for them. But when science was being lauded for good works, who among us argued that the credit belonged, not to science, but to those who used it for the benefit of mankind ?

We made this discovery when difficulties forced us to think more carefully about the place of science in society. Well as the old policy of laisserfaire in public relations worked for a time, it had encouraged in us an indolent complacency foreign to the critical spirit of inquiry. We may not enjoy the shocks that have aroused us any more than an investigator rejoices over facts that disprove an elegant hypothesis; but we must face the situation and see what we can do to mend it. I venture to suggest an obvious proposition that seems to me of controlling importance, and to 
point out certain corollaries that should guide both our attempts to understand the public relations of science and our future policy concerning them.

\section{IV}

The fundamental proposition is that scientific research is a social process as much as business, political, or religious activities are, and as such is interwoven with all other social processes, influencing them and being influenced by them. It is one among many social activities carried on by the peoples of our culture. Like all such processes, it is carried on by men who learn in childhood languages ill-suited to close thinking; by men who wish to eat, to make love, to win approval as well as to know ; by men who are reared in an environment of emotional likes and dislikes; by men who become so absorbed in their technical tasks that they have little energy to criticize the non-scientific parts of their own make-up. These scientific men form a tiny fraction of their communities. So far as they succeed in emancipating themselves from the misconceptions and prejudices prevailing in their social groups, they become by virtue of their partial emancipation queer creatures whose judgment most people mistrust outside of their specialties. Both the temperament that inclined them to research and the habits they form in research tend to make them awkward, ineffective, reluctant in appealing to the emotions that are so potent in influencing men.

It is difficult to see how a few scattered individuals, each accustomed to think for himself and to be critical even of his fellow inquirers, can guide public opinion except by slow educational processes. In the long run, their thinking may rule the world, just because it serves the purposes of mankind better than the traditional thinking it gradually replaces. But in the short run, others take of scientific discoveries only the parts that have an immediate application, and put these parts to such uses as they see fit-uses that serve whatever aims these others pursue. The prompt and potent influence of science upon society comes from these uses, good and bad, which scientists control only in small part.

Even in democratic countries, then, scientific men find it hard to bridge the gulf between their attitudes and those of the general public. In autocratic States the Governments might give scientists fuller opportunities to direct public policies than they enjoy in the democracies. But the autocratic States known to us are not built on that model. They are avid for science, to be sure, but only for science that is an uncritical servitor of ends the rulers determine. As between the difficult public relations confronting them in democracies and the shackling of free inquiry confronting them in autocracies, scientists cannot hesitate. Theirs is a world of intellectual freedom, not perfect alas, but the freest world the mind of man has yet created, and to let any authority under any pretence prescribe what conclusions they shall accept as scientific. is to stultify the spirit of science.

\section{V}

What, then, can scientists do to improve their public relations in communities where they are relatively free?

As I see the situation, they have two sets of opportunities and responsibilities; first, their opportunities and responsibilities as citizens ; second, their opportunities and responsibilities as investigators.

What scientific men can do as citizens is like what other intelligent men can do. If democracy is to work well, many people must form considered judgments upon a wide variety of problems. In forming a considered judgment on a given issue, what experts have to say should be taken into account. Who these experts are depends upon the character of the issue; more often than not contributions are needed from several kinds of specialists. All the many species of the genus scientist belong at one time or another in the list of desirable technical advisers ; so also do lawyers, business organizers, labour leaders, social workers, educators, civil servants, politicians, and so on. When matters within the competence of some group of scientists are involved, they should contribute what they know, whether formally invited to do so or not. To make their advice effective they should welcome help from people more skilled than themselves in the arts of popular presentation. On matters concerning which a scientist has no special knowledge, he should listen to others and form the best judgment he can from what they advise. To an individual this task of sifting and weighing different opinions is timeconsuming and difficult. On complicated issues organization is needed to bring into focus all the intelligence available in the community. Hence one of the civic duties incumbent upon all scientific men in common with other citizens is to support vigorously but critically the nascent movement toward organizing all the intelligence we possess for constructive study of social problems, before they become pressing emergencies that have to be dealt with in a hurry that allows no time for careful thinking.

The outside limits of what scientists can accomplish as citizens are set by their ignorance. Not merely does no individual have more than a tiny 
fraction of the knowledge that is needed; all the scientists of the country put together do not know enough to solve many of the problems that a democracy faces. In addition to the responsibilities they share with all other citizens, scientific men have the special duty of trying to increase the kind of knowledge required to deal intelligently with public problems. Their opportunities and responsibilities as citizens merge into their opportunities and responsibilities as investigators.

From the social point of view, the most urgent item in the unfinished business of science is to increase knowledge of human behaviour. If we had keener insight into individual psychology, we might not be able to alter fundamental drives, but we might be able to direct them into beneficent channels. Preaching righteousness doubtless prevents men from being as bestial as they might otherwise become. Appeals to reason prevent them from making as many errors as they otherwise might. But the moralist and the rationalist admit that the results of their efforts are grievously disappointing. Scientific men with any gift of selfanalysis realize that they have their own shares of selfishness and animosities. To subdue traits in oneself is hard enough to give an inkling of the difficulty of controlling them in society at large. Perhaps-and perhaps is all we can say - if we can come to a clearer understanding of how we behave, we can learn how to condition men so that their energies will go less into making one another miserable.

We all know that the social sciences lag far behind the natural sciences. That is because they deal with phenomena more complicated, more variable, and less susceptible of experimental manipulation. Since social investigators cannot experiment at will upon social groups, they cannot effectively apply to their problems the methods that have made the laboratory sciences strong.

Yet the case of economics and its sister sciences is not hopeless. The rapid growth of statistics is providing mass observations upon social behaviour of many kinds; the equally rapid growth of statistical technique enables us to learn more from a given array of data than our predecessors could. These materials and methods are making it possible to measure many social factors, some rather accurately, some roughly. Uniformities appear not only in averages, but also in the way in which individual items are distributed about their means. Statements in terms of probability can be substituted for vague statements about the effect a certain cause 'tends' to produce. True, work on this observational basis encounters many difficulties. It is limited by the variety, extent and accuracy of reliable data upon human behaviour. It is laborious, slow and expensive. In presenting his work a realistic investigator begins with a critique of his data and methods; he ends by setting forth the probable errors and limitations of his results, and the road from the beginning to the end may be long. Instead of definitive conclusions he thinks others should accept, he presents tentative approximations he expects others to improve. The work has not even the advantage of calling for less hard thinking than speculative theorizing; for the rèlations among the variables in the problem are seldom manifest of themselves. All that can be claimed for this type of work is that it deals with actual experience, that its results stand or fall by the test of conformity to fact, and that it grows cumulatively after the fashion of the observational sciences. But that is enough to give mankind strong reason for following this lead in seeking the knowledge required to improve social organization.

But science cannot flourish in the future and yield the fruits for which we hope unless freedom of thought prevails. The democratic way of life and the scientific way of thinking grew up together, each nourishing the other. If one now fails, the other will falter. Where democracy is suppressed to-day science is fettered; for autocracy cannot brook disinterested criticism of its dogmas or its practices. Freedom of scientific work in the years to come can be guaranteed only by preserving the institutions that secure freedom to all citizens.

Perhaps scientific men have more at stake than any other social group in the struggle to maintain democracy. To this struggle they can make a crucial contribution. The fact of free societies hangs upon the wisdom or folly of mass decisions. The gravest dangers to democracy come from within, not from without. They are ignorance, and propaganda that turns ignorance to its uses. The best way of dispelling ignorance is by diffusing knowledge. The most effective defence against meretricious propaganda is critical inquiry. John Dewey is warranted in saying that "the future of democracy is allied with spread of the scientific attitude". To foster this attitude among their fellow citizens by all means within their power is a duty incumbent upon us who cherish science. As teachers in schools and colleges we can help thousands to develop respect for evidence. As citizens we can be brave opponents of prejudice and hysteria. We can promote general understanding of the methods and results of science through our own writings or those of allies more skilled in popular exposition. These things we should do, not as high priests assured that they are always right, but as workers who have learned a method of treating problems that wins cumulative successes, and who would like to share that method with others. 